\title{
Nephrotic syndrome in Indian children
}

\author{
R. N. SRIVASTAVA, G. MAYEKAR, R. ANAND, V. P. CHOUDHRY, O. P. GHAI, \\ and H. D. TANDON \\ From the Departments of Paediatrics and Pathology, All India Institute of Medical Sciences, New Delhi, \\ India
}

\begin{abstract}
Srivastava, R. N., Mayekar, G., Anand, R., Choudhry, V. P., Ghai, O. P., and Tandon, H. D. (1975). Archives of Disease in Childhood, 50, 626. Nephrotic syndrome in Indian children. A clinicopathological study of 206 Indian children with the nephrotic syndrome showed a primary renal cause in $195(96 \%)$, of which $77 \%$ were boys. In 126 children ( 96 boys, 30 girls) onset of the disorder occurred before the age of 5 years. Renal biopsy showed minimal lesions in 150 patients $(77 \%)$; in 85 of these biopsy was done 3 months to 16 years after onset of the nephrotic syndrome. Significant renal histological abnormalities in $\mathbf{4 5}$ cases were labelled as mesangiocapillary 8 , mesangioproliferative 4 , proliferative with extensive crescents 2, membranous 3, focal segmental glomerulosclerosis 9, focal global glomerulosclerosis 2, advanced nonspecific 8, and mild proliferative 9. Nephritic manifestations were mainly associated with significant renal lesions, which were more frequently encountered when the onset of disease was after the age of 5 years. Clearance of proteinuria with corticosteroid therapy was practically confined to patients with minimal or mild renal histological changes.

Our findings suggest that the pattern of idiopathic nephrotic syndrome in Indian children is similar to that reported from Western countries.
\end{abstract}

Heavy proteinuria, clinically manifesting as the nephrotic syndrome, is almost always due to primary renal involvement in childhood. Studies from different parts of the world (Drummond et al., 1966; Tsao, Chan, and Gibson, 1969; White, Glasgow, and Mills, 1970; Habib and Kleinknecht, 1971) have shown a fair degree of homogeneity regarding the clinicopathological picture and therapeutic response. Reports from West Africa (Hendrickse and Gilles, 1963; Edington and Mainwaring, 1966), where quartan malaria accounts for a large number of cases, are an exception.

This study concerns clinicopathological observations and acute response to corticosteroid therapy in children with the nephrotic syndrome in Northern India.

\section{Patients and methods}

Over a 5-year period (1969-1973) we studied the renal histology in 206 children with the nephrotic syndrome. These patients comprised a homogeneous racial group representing the Northern Indian population and included, proportionately, patients from

Received 17 January 1975. different socioeconomic groups. Most of them had been treated earlier by other physicians and attended the All India Institute of Medical Sciences for expert care. Renal biopsy was not performed in 2 patients found to have unilateral renal agenesis. In 6 cases adequate renal tissue could not be obtained and in another 4 permission for biopsy was not given.

Age of onset was taken as that when oedema was first noticed. In all cases heavy proteinuria, hypoalbuminaemia (serum albumin $<2.5 \mathrm{~g} / 100 \mathrm{ml}$ ), and oedema were present. Hypertension was considered to be present when diastolic pressure of $>90 \mathrm{mmHg}$ was found in children over 6 years and $>80 \mathrm{mmHg}$ in younger children. Haematuria was indicated by the presence of more than 2-3 red cells/high power field in urinary sediment. Standard techniques were used for urine analyses and biochemical tests.

Renal biopsy tissue was fixed in $10 \%$ buffered formalin. Sections were cut at $3 \mu \mathrm{m}$ thickness and stained with H. \& E., P.A.S., periodic-acid silver methenamine, and Masson's trichrome. The slides were examined by two of us (R.N.S. and H.D.T.), the latter without the knowledge of clinical data. Interpretation and histological classification were done in accord with recent studies on this subject (Churg, Habib, and White, 1970; White et al., 1970; Habib and Kleinknecht, 1971; White, 1971; Arneil, 1971; 
Kincaid-Smith and Hobbs, 1972). Morphological features of the various forms of lesions have been well described in these reports, and only the following will be briefly discussed.

Mild, diffuse proliferation. The majority of the glomeruli showed mild hypercellularity involving the whole of glomerular tufts.

Mild, focal proliferation. Mild hypercellularity was seen involving less than $30 \%$ of the glomeruli.

Focal global glomerulosclerosis. About half of the glomeruli showed complete sclerosis, while the remainder appeared normal (Habib and Kleinknecht, 1971).

Mesangiocapillary glomerulonephritis. The term 'mesangiocapillary' has been preferred to 'membranoproliferative' (Kincaid-Smith, 1972).

The patients were treated with prednisone $2 \mathrm{mg} / \mathrm{kg}$ daily in 4 divided doses for 4 weeks, followed by 1.5 $\mathrm{mg} / \mathrm{kg}$ as a single dose on alternate days for another 4 weeks. Diuretics and antibiotics were given wherever indicated. Response was defined as disappearance of proteinuria.

\section{Results}

Secondary nephrotic syndrome. In 11 patients $(4 \%)$ the disorder was regarded as secondary. Aetiological conditions are listed in Table I. 3 patients had a severe nephrotic syndrome with nephritic manifestations lasting over 4 weeks in

\section{TABLE I}

Aetiology in 11 patients with the secondary nephrotic syndrome

\begin{tabular}{l|c}
\multicolumn{1}{c|}{ Aetiology } & No. \\
\hline $\begin{array}{l}\text { Congenital } \\
\text { Amyloidosis } \\
\quad \text { (1 rheumatoid arthritis, }\end{array}$ & 1 \\
$\quad \begin{array}{l}\text { 1 nonspecific aortitis) } \\
\text { Systemic lupus } \\
\quad \text { erythematosus }\end{array}$ & 2 \\
$\begin{array}{l}\text { Henoch-Schönlein vasculitis } \\
\text { Poststreptococcal acute } \\
\text { glomerulonephritis }\end{array}$ & 2 \\
\hline
\end{tabular}

each case. Renal biopsy showed changes characteristic of poststreptococcal acute glomerulonephritis. Clinical recovery took place in each case within 3-4 months. One patient with renal amyloidosis with undetermined cause was also found to have nonspecific aortitis (Takayasu's disease).

Idiopathic nephrotic syndrome. It was present in 195 cases (96\%). Age at onset and

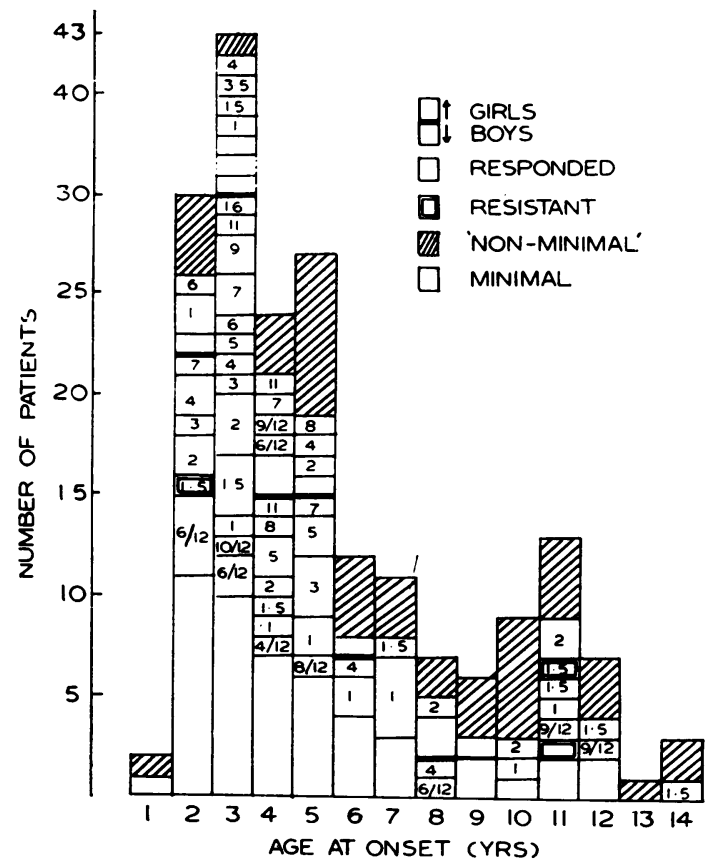

FIG. 1.-Distribution of renal histological lesions according to age at onset of nephrotic syndrome and sex. Figures in the columns indicate the duration (years) at biopsy. In the remainder biopsy was done within 3 months of onset. Response to corticosteroids in patients with minimal lesions is also shown. Sex incidence is not shown in "nonminimal' cases.

distribution of minimal and significant glomerular lesions are shown in Fig. 1. Onset occurred before the age of 5 years in 126 patients $(64 \%)$, and between 5 and 14 years in 69 patients $(36 \%)$. In each of these groups $77 \%$ were boys.

Renal histological findings. Table II shows the renal histological abnormalities in 195 patients with the idiopathic nephrotic syndrome. 150 patients $(77 \%)$ were classified as having minimal lesions and 45 significant changes.

Minimal lesions. Age at onset, sex, duration of disease at the time of renal biopsy, and response to corticosteroid therapy is shown in Fig. 1. There were 119 boys $(79 \%)$ and 31 girls $(21 \%)$. In 65 cases renal biopsy was done within 3 months of onset of disease, and in the remainder periods of up to 16 years elapsed before the biopsy was obtained. In 109 cases (76\% boys) onset occurred before the age of 5 years and in 41 cases ( $87 \%$ boys) 
TABLE II

Renal histological findings in 195 patients with idiopathic nephrotic syndrome

\begin{tabular}{|c|c|c|c|}
\hline Renal histology & No. & Boys & Girls \\
\hline $\begin{array}{l}\text { (A) Minimal lesions } \\
\text { (B) Significant lesions } \\
\text { Diffuse } \\
\text { (a) Proliferative } \\
\text { Mesangiocapillary } \\
\text { Mild proliferative } \\
\text { Mesangioproliferative } \\
\text { Proliferative with extensive } \\
\text { epithelial crescents } \\
\text { (b) Membranous } \\
\text { Focal } \\
\text { Segmental glomerulosclerosis } \\
\text { Global glomerulosclerosis } \\
\text { Mild proliferative } \\
\text { Advanced nonspecific }\end{array}$ & $\begin{array}{r}150(77 \%) \\
45(23 \%) \\
\\
8 \\
7 \\
4 \\
2 \\
3 \\
9 \\
2 \\
2 \\
8\end{array}$ & $\begin{array}{l}3 \\
5 \\
4 \\
2 \\
3 \\
\\
5 \\
2 \\
1 \\
5\end{array}$ & $\begin{array}{l}5 \\
2 \\
- \\
- \\
- \\
4 \\
- \\
1 \\
3\end{array}$ \\
\hline
\end{tabular}

TABLE III

Age and sex incidence related to renal histology

\begin{tabular}{|c|c|c|c|c|c|c|c|}
\hline \multirow{2}{*}{$\begin{array}{c}\text { Renal } \\
\text { histology }\end{array}$} & \multirow[t]{2}{*}{ No. } & \multicolumn{3}{|c|}{$\begin{array}{l}\text { Onset below the } \\
\text { age of } 5 \mathrm{yr}\end{array}$} & \multicolumn{3}{|c|}{$\begin{array}{l}\text { Onset between } \\
5 \text { and } 14 \mathrm{yr}\end{array}$} \\
\hline & & No. & Boys & Girls & No. & Boys & Girls \\
\hline $\begin{array}{c}\text { Minimal } \\
\text { lesions } \\
\text { Significant } \\
\text { lesions }\end{array}$ & 150 & 109 & $\begin{array}{c}83 \\
(76) \\
13 \\
(76)\end{array}$ & $\begin{array}{c}26 \\
(24) \\
4 \\
4 \\
(24)\end{array}$ & $\begin{array}{l}41 \\
28\end{array}$ & $\begin{array}{c}36 \\
(88) \\
17 \\
(61)\end{array}$ & $\begin{array}{c}5 \\
(12) \\
11 \\
(39)\end{array}$ \\
\hline Total & 195 & 126 & 96 & 30 & 69 & 53 & 16 \\
\hline
\end{tabular}

Figures in parentheses indicate percentages.

between 5 and 14 years (Table III). All except 3 patients responded to corticosteroid therapy.

Significant lesions. The various forms of renal histological abnormalities, with the sex distribution, are listed in Table II. Fig. 2 shows age at onset, sex, type of lesion, duration of disease at the time of renal biopsy, and response to corticosteroid therapy. Mesangiocapillary (8 cases) and focal segmental glomerulosclerosis (9 cases) were the commoner lesions. 8 patients showed advanced nonspecific changes. In 6 of these the nephrotic syndrome had been present for less than 3 months. 2 boys showed proliferative glomerulonephritis with extensive epithelial crescents (rapidly progressive glomerulonephritis), and another 3 membranous changes. 17 patients (24\% girls) had developed the nephrotic syndrome before the age of 5 years and 28 patients (39\% girls) between 5 and 14 years (Table III).
Relation between age at onset, sex, and renal histology (Fig. 1, Table III). The incidence of significant lesions increased with onset after the age of 5 years $(41 \%$ against $14 \%$ ). There also appeared to be a greater percentage of girls in the late onset group (11 out of 28 against 4 out of 17), but the difference was not significant.

Relation between renal histology, haematuria, hypertension, raised blood urea, and response to corticosteroids. The incidence of haematuria, hypertension, and raised blood urea in various histological groups, and response to corticosteroids are shown in Table IV. These abnormalities were rarely observed in those with minimal lesions, and were essentially associated with significant histological changes, especially with more severe lesions. Gross haematuria was observed in 3 cases with mesangiocapillary lesions, 2 cases with 

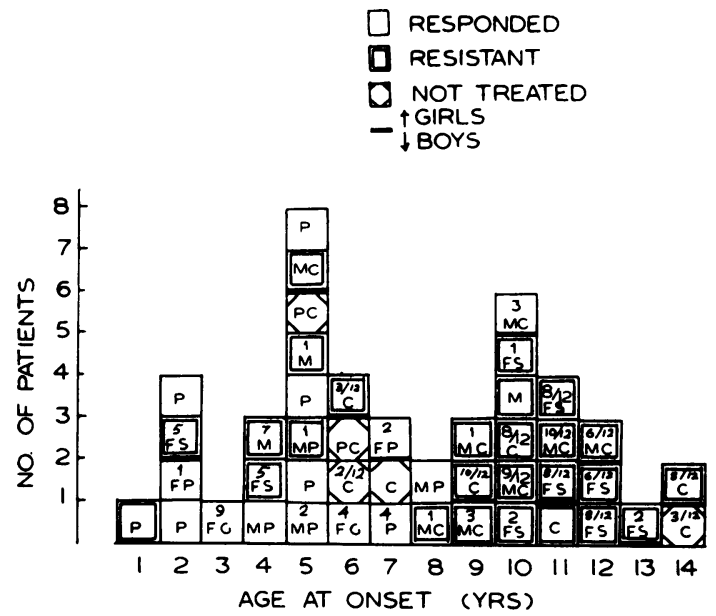

FIG. 2.-Analysis of cases with significant lesions. Figures in squares indicate duration (years) at biopsy. In the rest biopsy was done within one month. Letters indicate the type of lesion. $P$, mild diffuse proliferative; $F S$, focal segmental.glomerulosclerosis; FP mild focal proliferative; $F G$, focal global glomerulosclerosis; $M$, membranous; $M C$, mesangiocapillary; $M P$, mesangioproliferative; $P C$, proliferative with extensive crescents; $C$, advanced nonspecific.

proliferative lesions with extensive crescents, and 4 with advanced nonspecific lesions.

Response to corticosteroid therapy. All except 3 patients with minimal lesions responded to corticosteroid therapy with disappearance of proteinuria. Most of those showing milder forms of renal histological lesions (namely, mild proliferative, mesangioproliferative) also responded.
2 patients with focal global glomerulosclerosis, one of whom had microscopical haematuria and hypertension also showed disappearance of proteinuria. The majority of the patients with severe lesions did not respond. In a 5-year-old girl having the disorder for 2 months and showing mesangiocapillary lesions, proteinuria disappeared initially with prednisone, but recurred 3 months later and failed to clear with subsequent therapy with prednisone. None of the 9 patients showing focal segmental glomerulsclerosis responded. All except 9 patients with minimal lesions responding to prednisone therapy have shown relapse of the disorder. Of these, approximately $15 \%$ fall into the category of 'frequent relapsers' (having more than 3 relapses per year). Among them prolonged remission could be induced with the use of cyclophosphamide and 'alternate-day' prednisone (Srivastava et al., 1974).

\section{Discussion}

This study indicates that the pattern of nephrotic syndrome in Indian children is similar to that observed in Western countries (Drummond et al., 1966; Churg et al., 1970; White et al., 1970; Habib and Kleinknecht, 1971). Secondary nephrotic syndrome was found in only $4 \%$ of the patients. Malarial infection has almost disappeared from Northern India and it was not implicated in any case. The majority of the patients were boys of preschool age who showed minimal lesions on renal biopsy. With onset of the disorder after the age of 5 years, the incidence of significant renal histological abnormalities, as well as the proportion of girls, increased. The preponderance of nephrotic syn-

TABLE IV

Incidence of haematuria, hypertension, azotaemia, and response to corticosteroid therapy in various histological groups

\begin{tabular}{|c|c|c|c|c|c|}
\hline Renal histology & No. & Haematuria & Hypertension & $\begin{array}{c}\text { Raised } \\
\text { b!ood urea }\end{array}$ & $\begin{array}{l}\text { Response to } \\
\text { corticosteroids }\end{array}$ \\
\hline $\begin{array}{l}\text { (A) Minimal lesions } \\
\text { (B) Significant lesions } \\
\text { Diffuse } \\
\text { (a) Proliferative } \\
\text { Mesangiocapillary } \\
\text { Mild proliferative } \\
\text { Mesangioproliferative } \\
\text { Proliferative with crescents } \\
\text { (b) Membranous } \\
\text { Focal } \\
\text { Segmental glomerulosclerosis } \\
\text { Global glomerulosclerosis } \\
\text { Mild proliferative } \\
\text { Advanced nonspecific }\end{array}$ & $\begin{array}{l}8 \\
7 \\
4 \\
2 \\
3 \\
9 \\
9 \\
2 \\
2 \\
8\end{array}$ & $\begin{array}{l}8 \\
4 \\
4 \\
2 \\
2 \\
6 \\
2 \\
2 \\
8\end{array}$ & $\begin{array}{l}8 \\
1 \\
1 \\
2 \\
3 \\
\\
5 \\
1 \\
-8\end{array}$ & $\begin{array}{l}4 \\
- \\
\overline{2} \\
- \\
4 \\
- \\
\overline{8}\end{array}$ & $\begin{array}{c}1 \\
6 \\
3 \\
\text { Not used } \\
- \\
- \\
2 \\
2 \\
- \\
\text { Not used in } 3\end{array}$ \\
\hline
\end{tabular}


drome in boys is well established (Heymann, Makker, and Post, 1972; White, 1971) and reportedly confined to patients with minimal lesions. In the present study boys still predominated $(2: 1)$ among those with significant renal histological abnormalities, though in 2 of the severe forms of lesions, i.e. focal segmental glomerulosclerosis and mesangiocapillary lesions, the sex ratio was approximately equal.

Patients with minimal lesions formed a homogeneous group with regard to clinical profile and response to corticosteroid therapy. In 85 of such patients renal biopsy was examined 3 months to 16 years after the onset of the nephrotic syndrome. Most of these patients had suffered from several relapses but were steroid sensitive. It is fair to assume that these patients would have had minimal lesions to start with which did not change with the passage of time.

Significant renal histological abnormalities encountered included a variety of distinct patterns, whose relative distribution was similar to that observed in more recent reports (Churg et al., 1970; White et al., 1970; Habib and Kleinknecht, 1971). Some of the patients in the present study showing mild proliferative changes behaved as those with minimal lesions. The majority in the nonminimal group, however, conformed to a pattern that included association with nephritic manifestations and nonresponse to corticosteroids. Speculation regarding the initial type of lesion in 8 patients with advanced chronic changes is impossible. One of these patients, an 11-year-old boy, had the nephrotic syndrome with nephritic manifestations for 20 days. Renal biopys showed every glomerulus to be completely hyalinized. Such a feature has been reported to follow proliferative glomerulonephritis with extensive epithelial crescents within a very short period of time (Richardson et al., 1970). Focal global glomerulosclerosis (Habib and Kleinknecht, 1971) was shown in a 9-year-old boy who had developed the nephrotic syndrome at the age of 3 years and suffered from five relapses, each time responding to corticosteroids. An earlier renal biopsy examined 2 years after onset of the disease showed a mild, diffuse proliferative change. This was an instance where one type of glomerular lesion appeared to change into a different form.

The association of nephritic manifestations (haematuria, hypertension, azotaemia) with significant renal histological abnormalities and lack of response to corticosteroids is well-documented (White, 1971) and these features, therefore, can be predictive. The natural history of each of the various forms of renal histological lesions is probably different, and to group patients with such heterogeneous lesions (all causing heavy proteinuria) under the term 'nephrotic syndrome' would serve little purpose. This histological diagnosis is essential without implying that morphologically similar lesions might be aetiologically identical. In contrast, patients with minimal lesions behave uniformly, though with a varying long-term course.

Our observations support the view that renal biopsy is mandatory in patients with the nephrotic syndrome who manifest nephritic features and in those who do not respond to corticosteroids. In view of the generally poor prognosis in such patients an alternative therapeutic approach such as the use of immunosuppressive and anticoagulant agents might be indicated in selected cases (Kincaid-Smith, 1972).

We are grateful to Professor C. L. Pirani for comments on some of the renal biopsy slides. The secretarial assistance of $\mathrm{Mr}$. Mahender Lal is gratefully acknowledged.

\section{REFERENCES}

Arneil, G. C. (1971). The nephrotic syndrome. Pediatric Clinics of North America, 18, 547.

Churg, J., Habib, R., and White, R. H. R. (1970). Pathology of the nephrotic syndrome in children. Lancet, 1, 1299.

Drummond, K. N., Michael, A. F., Good, R. A., and Vernier, R. L. (1966). The nephrotic syndrome of childhood: immunologic, clinical and pathologic correlations. Fournal of Clinical Investigation, 45, 620 .

Edington, G. M., and Mainwaring, A. R. (1966). Nephropathies in West Africa. The Kidney, p. 488 . Ed. by F. K. Mostofi and D. E. Smith. Williams and Wilkins, Baltimore.

Habib, R., and Kleinknecht, C. (1971). The primary nephrotic syndrome of childhood. Classification and clinicopathologic study of 406 cases. Pathology Annual, p. 417. Ed. by S. C. Sommers. Appleton-Century-Crofts, New York.

Hendrickse, R. G., and Gilles, H. M. (1963). The nephrotic syndrome and other renal diseases in children in Western Nigeria. East African Medical fournal, 40, 186.

Heymann, W., Makker, S. P., and Post, R. S. (1972). The preponderance of males in the idiopathic nephrotic syndrome of childhood. Pediatrics, 50, 814.

Kincaid-Smith, P. (1972). The treatment of chronic mesangiocapillary (membranoproliferative) glomerulonephritis with impaired renal function. Medical fournal of Australia, 2, 587.

Kincaid-Smith, P., and Hobbs, J. B. (1972). Glomerulonephritis. A classification based on morphology with comments on the significance of vessel lesions. Medical fournal of Australia, 2, 1397.

Richardson, J.*A., Rosenau, W., Lee, J. C., and Harper, J., Jr. (1970). Kidney transplantation for rapidly progressive glomerulonephritis. Lancet, 2, 180.

Srivastava, R. N., Mayekar, G., Anand, R., Choudhry, V. P., and Ghai, O. P. (1974). Cyclophosphamide therapy in the management of nephrotic syndrome. Indian Pediatrics, 11, 767.

Tsao, Y. C., Chan, W. C., and Gibson, J. B. (1969). Persistent proteinuria in children. Archives of Disease in Childhood, 44, 443.

White, R. H. R. (1971). The nephrotic syndrome. Recent Advances in Paediatrics, p. 281. Ed. by D. Gairdner and D. Hull. Churchill, London.

White, R. H. R., Glasgow, E. F., and Mills, R. J. (1970). Clinicopathologic study of nephrotic syndrome in childhood. Lancet, $1,1353$.

Correspondence to Dr. R. N. Srivastava, Department of Paediatrics, All India Institute of Medical Sciences, New Delhi-110016, India. 